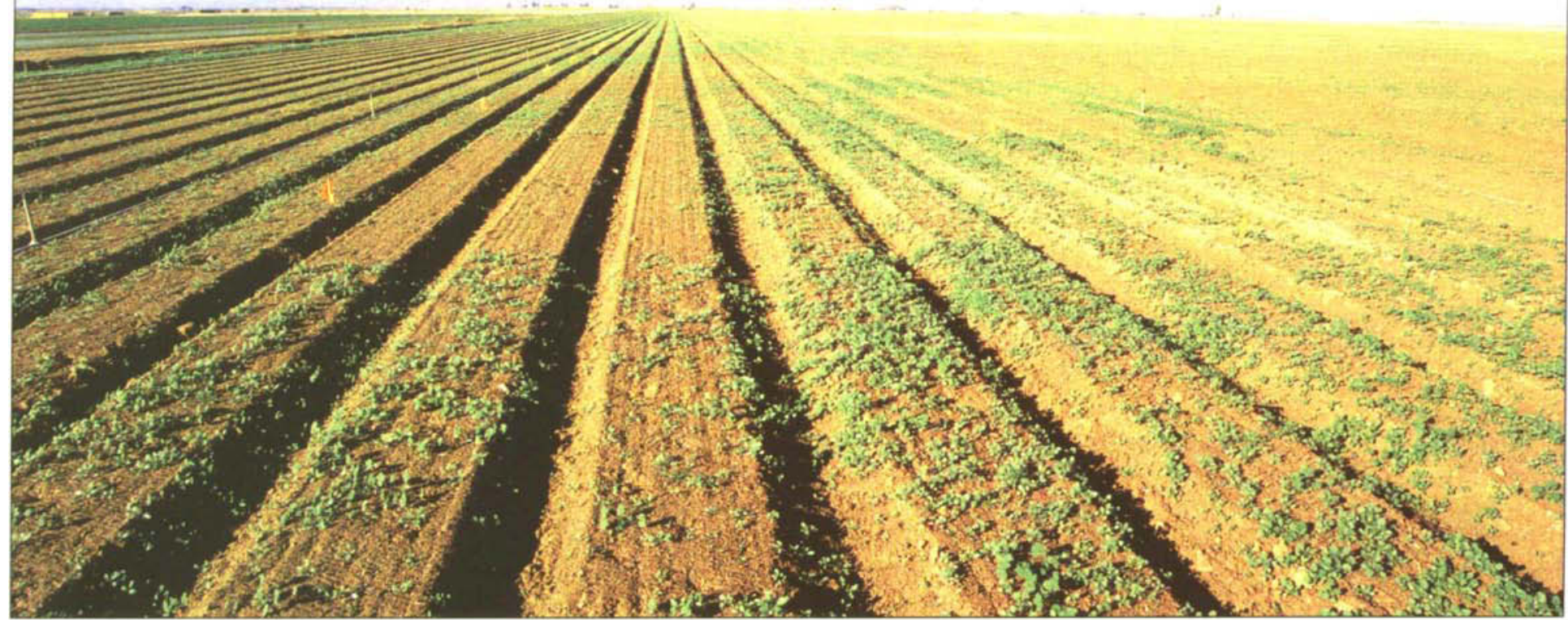

Onion field trials comparing bensulide and bensulide plus pendimethalin to DCPA and untreated control. Areas with green seed lines of onion without weeds are either DCPA or bensulide plus pendimethalin.

\title{
Combining bensulide and pendimethalin controls weeds in onions
}

\author{
Carl E. Bell 口 Brent E. Boutwell
}

DCPA was the principal preemergence herbicide for controlling weeds in onions until its manufacture was discontinued in 1996, although it may be reintroduced in 2001. The purpose of this research was to test the effectiveness of a combination of two herbicides, bensulide and pendimethalin, as a replacement weed-control treatment. Results are encouraging; this combination performed as well as DCPA in 12 onion field trials conducted in the Imperial Valley. Onion yields in fields treated with bensulide and pendimethalin were comparable to that of fields treated with DCPA.
$\mathrm{D}$ ry bulb onions (Allium cepa L.) are grown throughout California for fresh consumption and for processing into dried products. In 1997 there were about 46,000 acres of dry bulb onions in California, worth over $\$ 140$ million. Weed control in onions relies heavily on herbicides for several reasons. One reason is the close spacing of the crop. Most onions are direct seeded on the tops of beds spaced at 40 to 42 inches (Voss and Mayberry 1999a; Voss and Mayberry 1999b). The top of the bed, which is about 22 inches wide, has four to six seedlines just far enough apart to accommodate the mature bulbs. The crop is planted to a stand, so no thinning takes place. This spac- ing does not allow room for cultivation equipment. Any hand weeding that is done requires the use of asparagus knives, which are about 1.5 inches wide, or hand pulling rather than hoes. Using hoes would take out at least as many onions as weeds.

Another reason for reliance on herbicides is the slow germination of the onion from seed and the slow growth of small onions; both factors allow weeds to get a head start on the crop (Rubin 1990). A third reason for the reliance on herbicides is that onions do not compete well against weeds, especially early in the production cycle (Rubin 1990). Onions have narrow, upright leaves that do not shade the ground to inhibit competitors. 
These reasons demonstrate the need for preemergence herbicides, which are used when seeds are sown, to give the onions a chance early in the season against much quicker growing and competitive weeds. In addition, postemergence herbicides are used to keep fields weed-free in order to produce optimum yield, quality and ease of harvest.

DCPA has been the staple preemergence herbicide for onions for about 3 decades. It is a versatile and reliable herbicide, effectively controlling most annual weeds of onions, except those grown in soils high in organic matter. Unfortunately, in 1996, manufacture of DCPA herbicide was discontinued, leaving onion growers in North America and elsewhere without an effective alternative. Another manufacturer has acquired the production and marketing rights to DCPA and intends to have it available in the spring of 2001 . The only other currently registered preemergence herbicide for onions is bensulide. Previous experience with bensulide has shown that it does not control nearly as many weeds as DCPA and that there is some risk of crop injury at dosages normally used to achieve optimal weed control in other crops, such as melons and lettuce.

\section{Combining two herbicides}

At the suggestion of a local pest control adviser (see acknowledgements), we conducted experiments to test bensulide at a low rate combined with a very low rate of pendimethalin. Pendimethalin is a soil-active herbicide registered for onions that is used only after the crop has emerged. This herbicide is not registered for preemergence use because it has been shown to cause significant onion stand loss and injury at rates typically used when growing more tolerant crops, such as cotton. However, a very low rate of this herbicide may be safe enough for the crop while sufficiently improving weed control when combined with bensulide.

In 1997 we initiated field research to evaluate bensulide - applied alone at 4 and $6 \mathrm{lb}$ ai/acre (pounds of active ingredient per acre) - and a combined treatment of bensulide at $4 \mathrm{lb}$ ai/acre plus pendimethalin at $0.25 \mathrm{lb}$ ai/acre as alternatives to DCPA at $9 \mathrm{lb}$ ai/acre. For adoption of this treatment by onion growers in California, a successful treatment had to include weed control equivalent to DCPA and adequate crop safety. An important feature of these two alternative herbicide treatments was that they were both already registered for use in onions in the United States, including California, and only slight changes in label directions were required to allow the different uses tested here.

A selection of other herbicides, both old and new, was included in this research. The older herbicides were those that had shown some promise in previous research in California on onions. The new herbicides were those that had not been tested on onions, to our knowledge, but that were already registered on other crops, such as corn or soybean. Data on the results of these herbicides were not included be-

\begin{tabular}{llcc}
\multicolumn{4}{c}{ TABLE 1. Field locations, soil types and significant dates } \\
\hline \hline Field* & \multicolumn{1}{c}{ Soll type } & Planting/treatment date & Harvest date \\
\hline 1-Spruce 4 & Clay loam & Oct. 6, 1997 & NA \\
2-Redwood 46 & Holtville silty clay & Oct. 15, 1997 & May 27, 1998 \\
3-Orita 7 & Imperial-Glenbar silty clay & Oct. 22, 1997 & May 27, 1998 \\
4-Oasis 33 & Imperial silty clay & Oct. 22, 1997 & June 9, 1998 \\
5-Moss 3A & Imperial-Glenbar silty clay & Oct. 28, 1997 & June 11, 1998 \\
6-EHL 277 & Rositas fine sand & Nov. 7, 1997 & NA \\
1-Palm 34 & Imperial-Glenbar silty clay loam & Oct. 5, 1998 & May 18, 1999 \\
2-Redwood 33 & Indio loam & Oct. 6, 1998 & June 7, 1999 \\
3-New Spruce 12 & Holtville silty clay & Oct. 12, 1998 & April 16, 1999 \\
4-Orita 20 & Imperial-Glenbar silty clay loam & Oct. 14, 1998 & June 1, 1999 \\
5-O10 & Meloland very fine sandy loam & Oct. 26, 1999 & NA \\
6-Moss 3 & Imperial-Glenbar silty clay loam & Oct. 29, 1998 & June 4, 1999 \\
\hline "Field locations are irrigation canal names and gate numbers. & &
\end{tabular}

cause none met the criteria for adoption cited in the previous paragraph.

\section{Cooperative grower trials}

All of these experiments were conducted in cooperative grower fields in the Imperial Valley of southeastern California. In this area, onions are planted in the fall, around mid-October, for a spring harvest. The first year of the study, referred to as 1998 , spanned the winter season of 1997-1998. The second year, referred to as 1999 , spanned the 1998-1999 growing season. Twelve experiments are reported, six in 1998 and six more in 1999, each on a different field. Two in each year were on fields planted to dry bulb market onions (Imperial Valley Sweets); the rest of the experiments were on dry bulb dehydrator onions, those destined for drying and processing. We recorded soil type, planting date (which is the same as the herbicide application date) and harvest dates for each field (table 1).

Herbicides were applied by hand with a $\mathrm{CO}_{2}$-pressured sprayer at 30 psi, using 8003 flat fan nozzles and typically delivering 35 gallons per acre spray volume. After the preemergence herbicides were applied, the growers did all subsequent postemergence herbicide applications as part of their individual production practices. Herbicides varied by grower and field, but may have included bromoxynil and/ or oxyfluourfen for broadleaf weeds, and fluazifop, sethoxydim or clethodim for grasses. Fields were visually evaluated for weed control and crop vigor when the crop had one to two true leaves, before these postemergence herbicides were applied. Stand counts, a measure of onion plant density, were made on all experiments after the crop had finished germinating, generally at the two-to-four-leaf stage of growth. Yield data was obtained from nine of the fields when the rest of the field was being harvested, including all eight of the dehydrator onion fields but only one of the market onion fields.

Onion plant density and yield data were subjected to factorial analysis of 
variance. Because of significant interactions between years, locations and location within years with treatment, each trial was analyzed separately using two-way analysis of variance.

Treatment means were separated using Fisher's Protected LSD (0.05). Some of these treatment means were also compared using single degree of freedom class comparisons (orthogonal contrasts). Visual evaluations were not analyzed statistically.

\section{Weed control}

Four weed species - nettleleaf goosefoot, little mallow, London rocket and annual sowthistle - were abundantly represented in 4 (annual sowthistle and London rocket), 6 (little mallow) or 8 (nettleleaf goosefoot) of the 12 experimental sites (table 2). Ex- cept for nettleleaf goosefoot, bensulide alone did not control these weeds well enough to be acceptable to typical onion growers, especially at the lower dosage of $4 \mathrm{lb}$ ai/acre. These results are consistent with previous experiments with bensulide on other crops such as melons and lettuce. The combination treatment of bensulide plus pendimethalin controlled all four weed species. This was in spite of the fact that the rates used for each herbicide were lower than normally used in other row crops. A typical bensulide rate is $6 \mathrm{lb}$ ai/acre, compared to the $4 \mathrm{lb}$ ai/acre used here, and a rate of 0.75 to $1.0 \mathrm{lb}$ ai/acre is typical for pendimethalin instead of the $0.25 \mathrm{lb}$ ai/acre used in this study. This treatment was equivalent to the level of weed control achieved by
DCPA and satisfied one of our criteria for success.

\section{Crop safety and yield}

The other important criterion for this study was crop safety, which was measured as crop stand (population density) and yield. DCPA did not adversely affect onion density compared to the untreated control in any of the 12 field trials (table 3 ). Bensulide, however, did reduce onion density in five fields in the 1999 experiments, but did not affect any of the fields adversely in 1998. In 1999, bensulide, when applied at the higher rate, reduced onion density $4 \%$ to $70 \%$ in four of the fields compared to the DCPA treatment. In three fields, this rate of bensulide also resulted in crop densities $18 \%$ to $67 \%$ lower than the untreated control. The

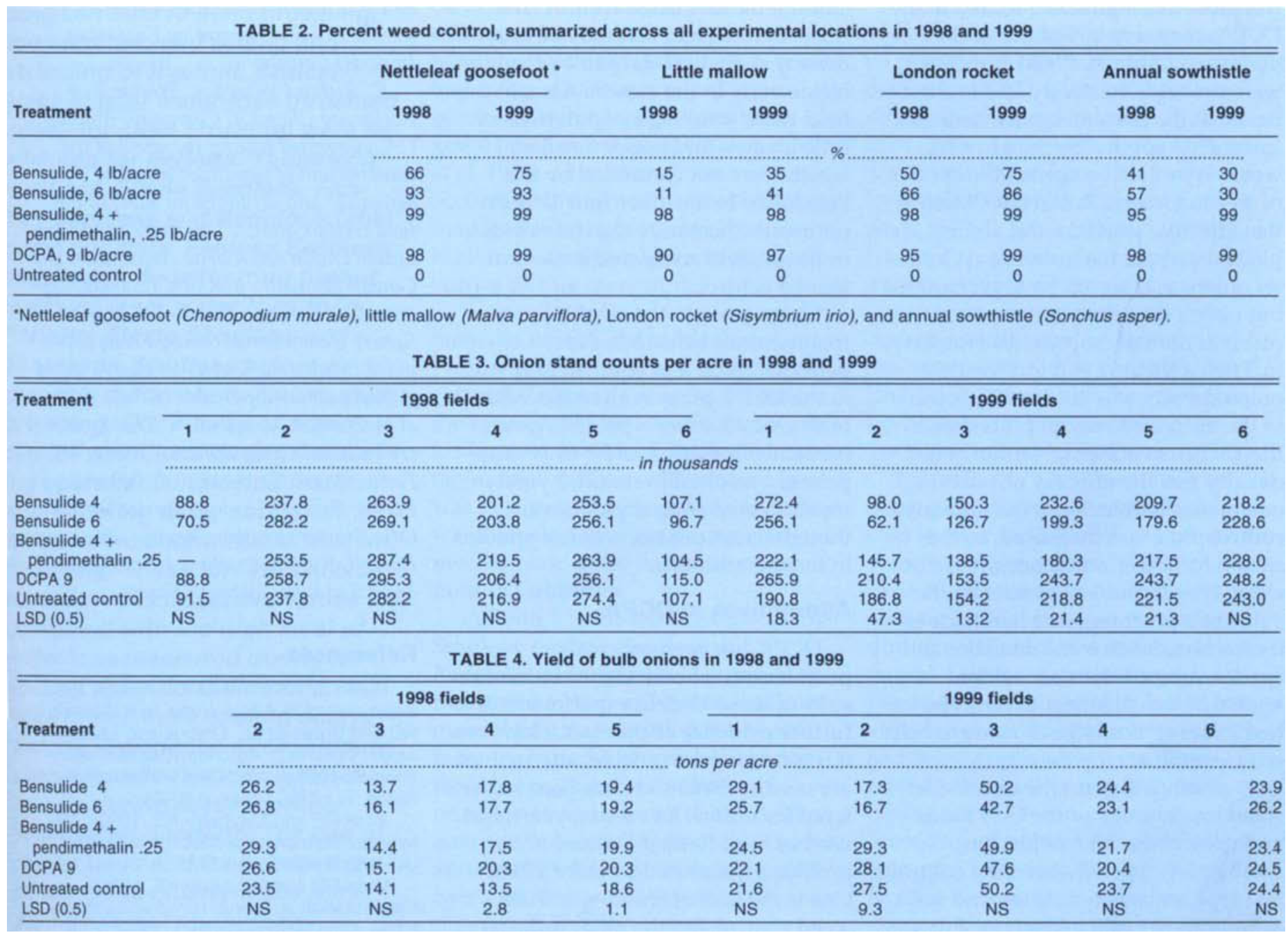


lower rate of bensulide also lowered onion density compared to DCPA in two fields, in one case by $14 \%$ and in the second case by $53 \%$. In one field, the lower rate of bensulide reduced density by $48 \%$ compared to the untreated control, but densities were also higher in two of the fields.

The combination treatment of bensulide plus pendimethalin also had an effect on onion density in 1999. Stand counts for the combination treatment were lower than the untreated control in fields 3 and 4, and lower than DCPA in fields 1 through 5 . In the worst case, onion density was reduced by $31 \%$. Onion density was also lower than the low rate of bensulide alone in fields 1 and 4 , but higher in field 2.

Onion density in the untreated control plots was equivalent to that in the DCPA treatment in 9 of the 12 field experiments (table 3 ). Weed densities were probably relatively low in these fields, or the postemergence herbicide treatments applied by the growers were very effective against the species of weeds present. Rubin (1990) noted that effective weed control accomplished early in the growing cycle, after onions and weeds have germinated but before they start to compete, can result in normal crop yields. However, in 3 fields (fields 1, 4 and 5) in 1999, onion density was $10 \%$ to $28 \%$ lower in the untreated control plots than in the DCPA treatment. Neither weed density nor the efficacy of postemergence herbicides in the untreated control plots was measured, so the reason for lower onion density is not clear. These results demonstrate the value of a preemergence herbicide in these cases. Since weed densities and species compositions are seldom known before planting, preemergence herbicides typically have value to help ensure optimal crop density.

We cannot explain the reason for stand loss in some of the 1999 fields and none of the 1998 fields, but weather has typically been the culprit. Soil type, especially texture, and soil salinity were evaluated as possible ex- planations, but no reasonable connection was apparent. A reduced crop stand does not always equal a reduced yield, since onions compensate to some extent by producing larger bulbs. However, there can be an effect on quality and marketability of the bulbs if the stand is uneven.

In six of the nine fields where we obtained yield data, there was no statistical difference in crop yield between treatments and the untreated control (table 4). This lack of yield difference may also be due to the fact that weed densities in these trials were low and/or postemergence herbicide treatments were effective enough to prevent yield loss. In 1999, onion yield from the two bensulide alone treatments in field 2 were significantly lower than the other treatments, including the untreated control. The cause of this yield loss may be onion density reductions caused by the herbicide early in the season. Also, in this field there were high populations of little mallow and London rocket, which were not controlled by the bensulide. In the other four 1999 experiments, herbicide use did not raise or lower yield compared to the untreated control.

Onion yield in the combination treatments of bensulide plus pendimethalin was equivalent to that in the DCPA plots in all of the fields in both years. Lack of a preemergence herbicide in fields 4 and 5 in 1998 apparently resulted in reduced yield in the untreated control plots, even though onion density was not affected in these treatments.

\section{Alternatives to DCPA}

\section{DCPA has been an excellent} preemergence herbicide for onions; results of these 12 field experiments are further evidence of that fact. However, if it is no longer available, alternatives are needed. Bensulide has been registered for onions for several years, but use has been limited because of two problems illustrated by these trials. One is the lack of broad-spectrum weed control and the other is the ten- dency to injure onions and affect onion stand. The combination treatment of bensulide and pendimethalin shows promise as a substitute for DCPA. However, these results are currently valid only for onion production in the low desert areas of California; they need to be duplicated in other areas and under different environmental conditions to encourage widespread adoption of this treatment. In addition, several newer herbicides that have more desirable environmental and toxicological characteristics than these old herbicides as identified by the U.S. Environmental Protection Agency are being tested in a variety of locations in California.

C.E. Bell is Weed Science Farm Advisor and B.E. Boutzuell is Staff Research Associate II, UC Cooperative Extension, Imperial County.

C. Richard Waegner, President of Rockwood Chemical Company, Brawuley, $C A$, suggested testing the effect of the combination of pendimethalin and bensulide and arranged for most of the field trial locations. The American Dehydrator Onion and Garlic Association and Gowan Company provided financial support. Jose Larios of Rogers Foods and Robert Denewiler of Gilroy Foods provided invaluable field assistance. Several growers donated portions of their fields at no cost for these studies. These growers included Craig Elmore, Desert Sky Farms; Mark Osterkamm, Osterkamp Farms; Robert Fleming, Spruce Farms; Otis Kramer, Kramer Farms; Carl Russell, Russell Brothers Farms; and Mike Sudduth, Sudduth Farms.

\section{References}

Rubin B. 1990. Weed competition and weed control in Allium crops. In Rabinowitch $\mathrm{HD}$ and Brewster JL. Onions and allied crops. Volume II: Agronomy, Biotic Interactions, Pathology, and Crop Protection. Boca Raton, FL: CRC Press. p 63-84.

Voss RE and Mayberry KS. 1999a. Dehydrator bulb onion production in California UC-DANR publication 7239.

Voss RE and Mayberry KS. 1999b. Fresh-market bulb onion production in California. UC-DANR publication 7242 